\title{
A PRÁTICA DA COMPOSTAGEM PARA A ADUBAÇÃO ORGÂNICA PELOS AGRICULTORES FAMILIARES DE SANTA ROSA/RS
}

\author{
Aline Guterres Ferreira ${ }^{1}$ \\ Sílvia Naiara de Souza Borba ${ }^{2}$ \\ José Geraldo Wizniewsky ${ }^{3}$
}

\begin{abstract}
Resumo
O uso da compostagem para a adubação orgânica é uma prática disseminada no meio rural, considerado prático pelos agricultores familiares, pois possibilita que se utilize menos agroquímico e seja menos dependente que insumos externos. Neste trabalho, buscou-se conhecer e caracterizar as práticas agrícolas utilizadas pelos agricultores do município de Santa Rosa/RS. Os resultados obtidos são provenientes do convênio entre a Prefeitura de Santa Rosa/RS e a Universidade Federal de Santa Maria, para o diagnóstico da realidade rural do município. Utilizou-se como metodologia a entrevista semiestruturada com 283 agricultores da região. Os dados obtidos pelo estudo revelam que a maioria dos agricultores, ou seja, aproximadamente $75 \%$, utilizam a compostagem para a adubação orgânica de pequenas hortas. Essa prática deve ser melhor estudada, para fornecer aos agricultores recomendações corretas.

Palavras-chave: adubação orgânica, agricultura familiar, compostagem.
\end{abstract}

\section{INTRODUÇÃO}

A compostagem é uma técnica milenar, praticada inicialmente pelos chineses há mais de cinco mil anos. Nada muito diferente do que natureza faz a bilhões de anos desde que surgiram os primeiros microrganismos decompositores. Seguindo o exemplo da floresta, onde observamos que cada resíduo, seja ele de origem animal ou vegetal, é reaproveitado pelo ecossistema como fonte de nutrientes para as plantas que, em última análise, são o sustentáculo da vida terrestre. Pois bem, quando procedemos com a compostagem estamos seguindo as regras da natureza e destinando corretamente nossos resíduos.

\footnotetext{
${ }^{1}$ Zootecnista e Mestranda do Programa de Pós-Graduação em Extensão Rural da Universidade Federal de Santa Maria e Acadêmica do Curso Especial de Graduação para Formação de Professores para a Educação Profissional, UFSM. Email: alinegf@ zootecnista.com.br

${ }^{2}$ Acadêmica do Curso de Zootecnia da Universidade Federal de Santa Maria - UFSM.

${ }^{3}$ Professor Doutor do Departamento de Educação Agrícola e Extensão Rural da Universidade Federal de Santa Maria - UFSM.
} 
Produzir adubo na propriedade rural é uma prática fácil porque a matéria prima a ser usada é obtida de resíduos orgânicos como o lixo doméstico e os restos de culturas (folhas, ramos, cascas de frutos, etc.), ou seja, toda matéria que se seria descartada.

A compostagem produz o adubo que é essencial para o solo na melhoria de sua estrutura e fertilidade, além de proporcionar às culturas um vigor extraordinário com aumento na sua produtividade. Isto pode ser verificado na satisfação do produtor rural que realiza tal tarefa.

A compostagem é um processo biológico em que os microrganismos transformam a matéria orgânica, tais como, dejetos de animais (estercos de aves, bovinos, suínos, ovinos, equinos, etc.), cascas e bagaços de frutas e caroços não comercializados, resíduos de culturas (cascas de arroz, palha de milho, vagem seca de feijão, casca seca de café), folhas e ramos de mandioca, bananeira e demais culturas, serragem, restos de capim (colonião, elefante, brachiara, quicuiu, etc.), além desses materiais, também pode ser utilizada para enriquecer o adubo orgânico: farinha de osso, cascas de mexilhão e de caranguejo (trituradas), cinzas e terra preta, além de como estrume, folhas e restos de comida, num material semelhante ao solo, a que se chama composto, e que pode ser utilizado como adubo.

Tradicionalmente a compostagem é vista como uma prática usual em propriedades rurais de pequeno porte, caracterizada como agricultura familiar. Pois é uma estratégia do agricultor para transformar os resíduos agrícolas em adubos essenciais para a prática da agricultura orgânica, se tornar menos dependente dos insumos advindo do exterior da propriedade e dar destino final correto a esses resíduos.

O composto serve para enriquecer solos pobres, melhorando a sua estrutura e permitindo uma boa fertilidade, também aumenta a capacidade das plantas na absorção de nutrientes (macro e micro), fornecendo substâncias que estimulam seu crescimento. Podem-se citar os macro nutrientes - N, P, K, Ca e Mg e os micronutrientes - Bo, Cl, $\mathrm{Cu}, \mathrm{Co}, \mathrm{Na}$, assim facilita a aeração do solo, retêm a água e reduz a erosão provocada pelas chuvas. $\mathrm{O}$ adubo funciona como inoculante para o solo, acumulando os macro e microrganismos (fungos, actinomicetos, bactérias, minhocas e protozoários) que são formadores naturais do solo.

A composteira (Figura 01) é uma estrutura própria para o depósito e processamento do material orgânico. Geralmente são feitas em locais pequenos e possui 


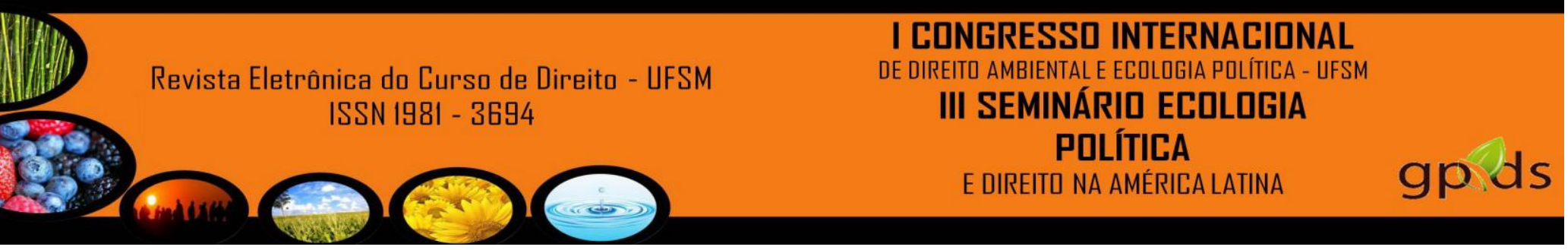

econômica está bastante presente nessa atitude e também dar um destino final correto para esses materiais orgânicos.

Os resultados apresentados neste trabalho decorrem de uma pesquisa realizada através de um convênio entre a Prefeitura do Município de Santa Rosa/RS e o Grupo de Pesquisa em Extensão Rural Aplicada/Universidade Federal de Santa Maria (UFSM), para realização do diagnóstico da realidade rural do município.

\section{UNIVERSO ESTUDADO E A METODOLOGIA}

O município de Santa Rosa/RS, (Figura 02), localiza-se a uma latitude de

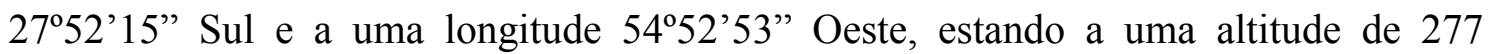
metros. A área total do município é de $489,8 \mathrm{Km}^{2}$ e encontra-se a uma distância de 500 $\mathrm{km}$ da cidade de Porto Alegre/RS. Segundo o Instituto Brasileiro de Geografia e Estatística (IBGE), Censo 2009, a população estimada do município é de 66.059 habitantes, com uma densidade demográfica de 133,1 hab./ $\mathrm{Km}^{2}$. Deste total de habitantes, aproximadamente $87,7 \%$ residem na área urbana e 12,3\% na área rural. (Fundação de Economia e Estatística- FEE, 2008). A região é caracterizada por apresentar matriz produtiva baseada nos cultivos da soja, milho, trigo e gado de leite e de corte. 
III SEMINÁRII ECDLOGIA

através das entrevistas com os agricultores, portanto, representam as observações e declarações fornecidas pelos mesmos.

As propriedades escolhidas para o estudo foram aquelas que se enquadravam que apresentavam significativa presença de estabelecimentos de agricultura familiar. $\mathrm{O}$ estudo foi realizado durante o segundo semestre de 2007 até o segundo semestre de 2009, num total de 283 propriedades rurais entrevistadas.

O trabalho de campo foi realizado através do agrupamento de localidades rurais como unidades de pesquisa (Figura 03), prevendo a possibilidade de realização do trabalho num horizonte temporal de dois anos e abrangendo localidades próximas e com características semelhantes, a fim de possibilitar a análise das entrevistas totalizando 283 entrevistas.

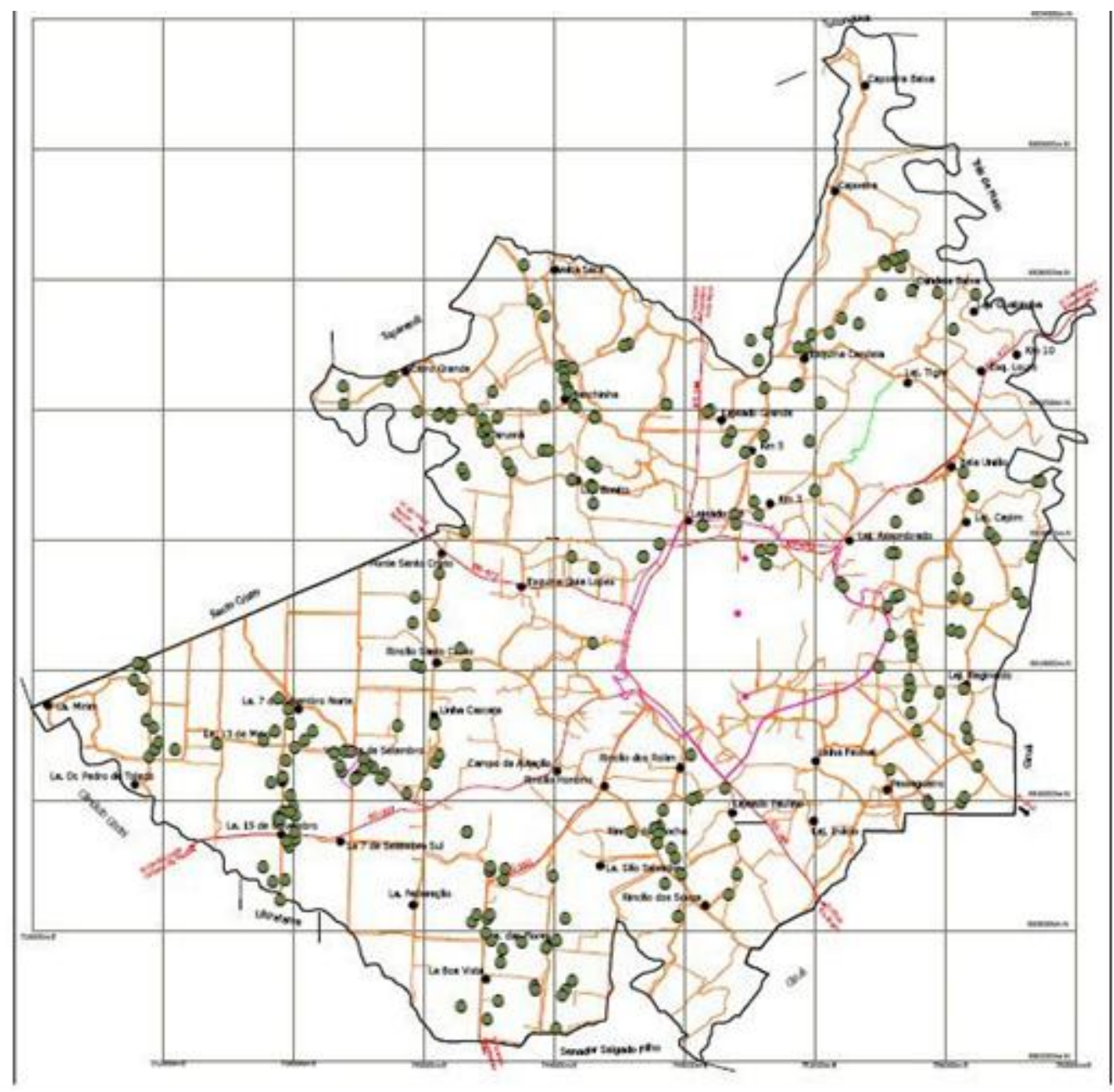

Figura 03. Distribuição das propriedades amostradas para o Estudo de Realidade Rural no Município de Santa Rosa/RS. 

agroquímico, pois tem a consciência que causa muitos malefícios a saúde, também o preço dos insumos estão muito elevados para a utilização em pequena escala e por fim a responsabilidade de dar um destino final correto para resíduos orgânicos, aproveitando para aumentar a produtividade de suas hortas.

A todos esses que utilizam a compostagem para a produção de adubo orgânico, também enfatizaram que cresceram assistindo e ajudando a seus pais e familiares na construção de composteiras, no seu manejo e cuidados, na produção do adubo orgânico e na utilização desse composto nas hortas e pequenas lavouras ao redor da casa. Declarando que essa atividade é advinda da herança que eles receberam de seus pais, que eram de origem alemã, italiana, russa e polonesa, característico da colonização realizada na região norte do Estado do Rio Grande do Sul.

Também muitos relataram que essa prática está associada não somente a herança repassada de seus pais, mas sim a conscientização da responsabilidade ambiental que muitos prezam. E pretendem ensinar isso para seus filhos e netos, porque isso também está nas tradições e cultura da imigração de suas famílias.

O teor ótimo de umidade para compostagem aeróbica compreende-se entre 50 a $60 \%$, o ajuste de umidade pode ser feito por mistura de componentes. Na prática também se verifica que depende da eficácia do arejamento (manual ou mecânica) da massa em compostagem, nas características físicas dos resíduos (estrutura, porosidade etc.) e na carência microbiológica da água.

Altos teores $(\sim 65 \%)$ fazem com que a água ocupe os espaços vazios da massa, impedindo a livre passagem do oxigênio, o que poderá provocar o aparecimento de zonas de anaerobiose. Baixos teores de umidade (inferiores a 40\%) inibem, por sua vez, a atividade microbiológica, diminuindo a taxa de estabilização. O teor ótimo de umidade é de, aproximadamente, de 55\%.

A qualidade do composto (Figura 04) obtido pode ser definida em termos de composição de nutrientes e de matéria orgânica, $\mathrm{pH}$, textura, distribuição do tamanho das partículas, percentagem de sais, odor residual, grau de estabilidade e maturação, presença de organismos patogênicos e concentração de metais pesados. Infelizmente, estes valores são bastante variáveis e não existe consenso quanto às quantidades ideais para estes parâmetros. 
III SEMINÁRII ECDLOGIA

POLÍTICA

riscos para a saúde pública. A ausência de microrganismos patogênicos no composto final é extremamente importante, uma vez, que este vai ser utilizado em aplicações às quais as pessoas vão estar diretamente expostas. No entanto, o controle desses microrganismos pode ser facilmente alcançado, quando o processo é eficiente e controlado. A maior parte dos microrganismos patogênicos são facilmente destruídos às temperaturas e tempos de exposição utilizados nas operações de compostagem $\left(55^{\circ} \mathrm{C}\right.$ durante 15 a 20 dias).

\section{CONSIDERAÇÕES FINAIS}

O diagnóstico da realidade rural do município de Santa Rosa/RS desenvolvido pelo Grupo de Pesquisa Extensão Rural Aplicada da UFSM, possibilitou constatar que a prática da compostagem ainda está muito presente no meio rural do município para a adubação orgânica de hortas e pequenas lavoura. Isso se dá pela conscientização dos agricultores em não utilizar agroquímicos em culturas que irão para sua alimentação, de seus familiares e amigos, pelos preços altos dos insumos para aplicação em pequenas escalas e a responsabilidade em descartar resíduos orgânicos em ambientas adequados.

As características das composteiras que os agricultores estão construindo estão de acordo com as recomendações técnicas dos órgãos de fomento para o desenvolvimento rural da região, igualmente o manejo dessas composteiras está adequado à realidade dos mesmos apesar de alguns problemas encontrados. Isso é muito importante, pois deve se levar em consideração, que essas composteiras são para uso doméstico de agricultores familiares.

Também foi declarado que essa prática é herança de seus ancestrais, que já utilizavam o sistema de compostagem para adubação orgânica, como grande parte dos agricultores são de origem de alemãs, italianos, russos e poloneses, vemos que essa prática é oriunda da imigração europeia característica da colonização do norte do Estado do Rio Grande do Sul.

Entretanto, é necessário que os centros de ensino e pesquisas invistam em projetos que buscam novas práticas, visando à melhoria e a sustentabilidade dos processos produtivos, nos aspectos econômicos, sociais e ambientais, além de buscar a 


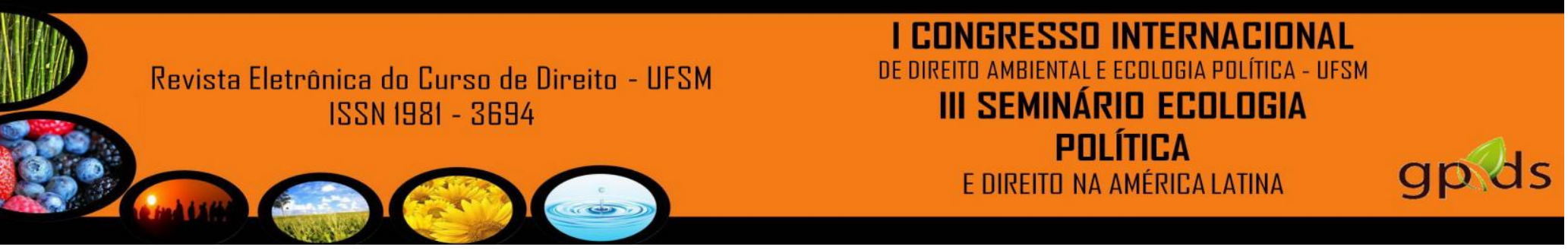

conscientização ambiental de todos os agricultores para a multiplicação dos usos e adoção de novas práticas com princípios orgânicos.

Que com trabalho e empenho num futuro próximo essa produção orgânica pode passar de doméstica para comercial, oferecendo para os agricultores uma renda extra, pois estaria agregando valor a seus produtos sem a utilização de agroquímicos, que causam malefício a saúde.

\section{REFERÊNCIAS}

FUNDAÇÃO DE ECONOMIA E ESTATÍSTICA. FEE. Disponível em: < http://www.fee.tche.br/sitefee/pt/content/resumo/pg_municipios.php?letra=S $>$. Acesso em: 12 jun. 2012.

INSTITUTO BRASILEIRO DE GEOGRAFIA E ESTATÍSTICA. IBGE. Disponível em: < http://www.ibge.gov.br/home/>. Acesso em: 12 jun. 2012.

OLIVEIRA; A. M. G.; AQUINO; A. M.; NETO; M. T. C.; Compostagem Caseira de Lixo Orgânico Doméstico. Circular 76. Ministério da Agricultura Pecuária e Abastecimento. Bahia, dezembro 2005.

PARÁ. Secretaria Executiva de Ciência, Tecnologia e Meio Ambiente. II. Programa Paraense de Tecnologias Apropriadas. Compostagem: produção de adubo a partir de resíduos orgânicos. Belém: III. Título. IV. Série, 2003. 